\title{
Tuberculous pleural effusion: experience with six months of treatment with isoniazid and rifampicin
}

\author{
C Cañete, I Galarza, A Granados, E Farrero, R Estopà, F Manresa
}

\begin{abstract}
Background - Tuberculous pleurisy is associated with small numbers of bacteria. Due to the low rate of primary resistance to antituberculous drugs a two-drug regimen was used to treat the condition.

Methods - Patients received isoniazid $5 \mathrm{mg} / \mathrm{kg}$ and rifampicin $10 \mathrm{mg} / \mathrm{kg}$ daily for six months. Clinical, radiological, and haematological assessments were performed during treatment and patients were followed up for a median period of 41 (range 6-96) months.

Results - One hundred and thirty patients were studied with a mean age of 27 (range 11-53) years. Seven were withdrawn due to parenchymal disease and eight were lost to follow up during the treatment period. Side effects during treatment were frequent $(20.7 \%)$, but only three patients required a change in medication. No treatment failures were observed. One hundred and fifteen patients completed therapy and were followed up for 41 (range 6-96) months with no evidence of a relapse. Conclusions - Tuberculous pleurisy responds well to a two-drug regimen of antituberculous therapy given for six months.
\end{abstract}

(Thorax 1994;49:1160-1161)

Treatment for tuberculosis has become shorter, more efficient, and economical, and yet should still achieve a low rate of relapse. ${ }^{\prime}$ Short regimens are effective on forms of tuberculosis with few bacilli when bactericidal drugs to which the microorganism is susceptible are used. $^{23}$

Tuberculous pleurisy is associated with low bacterial populations, as shown by the high index of negative sputum smears and the scarcity of positive cultures of pleural fluid and biopsy material. ${ }^{4}$ Treatment of tuberculous pleurisy with two bactericidal drugs may therefore be effective with a minimal risk of resistance to either drug. The results of eight years of experience with a six-month treatment regimen of two drugs are presented.

\section{Methods}

Patients admitted to hospital for tuberculous pleurisy without evidence of lung parenchymal involvement were included in the study. Patients with HIV infection were excluded.

Diagnosis of tuberculous pleurisy was made if patients met at least one of the following criteria: (1) pleural exudate with positive culture for Mycobacterium tuberculosis; (2) pleural biopsy culture positive for $M$ tuberculosis; (3) caseating granulomas with Langhans giant cells, epithelioid cells and lymphocytes, or (4) compatible clinicoradiological picture plus two or more of the following: age $<40$ years, PPD $>6 \mathrm{~mm}$ or conversion using 5 units of tuberculin PPD-S, lymphocytic pleural fluid ( $>70 \%$ lymphocytes), pleural fluid levels of adenosine deaminase activity (ADA) $>60 \mathrm{U} / \mathrm{ml}$ (UV enzymatic kinetic automatised method with an $\mathrm{NADH}$ substratum at $37^{\circ} \mathrm{C}$ ).

Isoniazid $5 \mathrm{mg} / \mathrm{kg} /$ day or a total daily dose of $300 \mathrm{mg}$, and rifampicin $10 \mathrm{mg} / \mathrm{kg} / \mathrm{day}$ or a total daily dose of $600 \mathrm{mg} /$ day were given once a day for six months.

On discharge patients were followed up as outpatients every two months to monitor the clinical and radiological course of disease, drug compliance, and possible side effects. After the end of treatment patients were seen every year.

Baseline liver enzymes (ALT, AST, GGT), bilirubin, and complete blood count were measured before starting treatment and every two months during treatment. If the liver enzyme levels increased to no more than twice their baseline values in a non-symptomatic patient, treatment was continued but testing became more frequent. If enzyme levels increased to more than twice their baseline levels and/or the patient developed epigastric pain, nausea, vomiting, jaundice, fever, arthralgia, rash, or haematological reactions, the drugs were changed and the patient was excluded from the study.

Diagnosis of tuberculous pleurisy in 130 patients

\begin{tabular}{lc}
\hline Criteria & No. of patients \\
\hline Granulomas in pleural biopsy material & $40(31 \%)$ \\
Positive culture of pleural fluid/biopsy & $16(12 \%)$ \\
Positive histology and culture & $26(20 \%)$ \\
Four minor diagnostic criteria* & $26(20 \%)$ \\
Three minor diagnostic criteria & $18(14 \%)$ \\
Two minor diagnostic criteria & $4(3 \%)$ \\
\hline
\end{tabular}

* Minor diagnostic criteria: age $<40$ years, tuberculin tes $>6 \mathrm{~mm}$, lymphocytic exudate and ADA $>60 \mathrm{U} / \mathrm{ml}$ in pleural fluid. 


\section{Results}

Between January 1985 and December 1992 130 patients entered the study. Microbiological and/or histological evidence of $M$ tuberculosis was obtained in $82(63 \%)$ patients (table). All but one patient was white and 53\% were men; the mean age was 27 (range 11-53) years.

Smears for $M$ tuberculosis were negative in all sputum samples (54), gastric aspirates (35), and pleural effusions (123). Lowenstein culture was positive in four sputum samples and in one gastric aspirate, and these patients were excluded and treated with a conventional regimen including rifampicin, isoniazid, and pyrazinamide (2RIZ/4RI). Pleural fluid culture became positive in 32 of the 123 samples analysed (26\%).

Pleural biopsy was performed in 92 patients, taking at least three samples in each procedure; 69 biopsies (75\%) showed tuberculous granulomas.

Twenty seven patients $(20 \cdot 7 \%)$ reported adverse reactions during treatment; 24 were able to continue the treatment, 17 had a twofold or less increase in liver enzymes, five had symptomatic hepatitis, and two had febrile reactions. One of the three remaining patients developed hepatitis, one drug-induced fever plus hepatitis, and one gastrointestinal intolerance. In these three cases treatment was changed. No adverse haematological reactions were observed.

Fifteen patients $(12 \%)$ did not complete treatment. Seven were withdrawn with evidence of radiological and/or microbiological parenchymal involvement and eight were lost to follow up.

The 115 patients who completed treatment showed complete clinical resolution. They were then followed up for a median period of 41 (range 6-96) months. No patient relapsed during follow up.

\section{Discussion}

Uncomplicated forms of tuberculous pleurisy are assumed to contain few bacilli $\left(10^{3}-10^{5}\right)$ and to affect young people. ${ }^{45}$ Its frequency depends on the incidence of the disease, and in Spain it represents $23.3 \%$ of all cases. ${ }^{6}$

The prevalence rate in our area is 50/100 000 inhabitants. The latest published data on primary resistance in Barcelona are: $0 \cdot 4-4.8 \%$ for isoniazid, $0 \%$ for rifampicin, and $2 \cdot 8-3 \cdot 4 \%$ for streptomycin. ${ }^{7}$ Despite the HIV epidemic, no increase in primary resistance has been observed in the last five years. ${ }^{8}$

We used a short two-drug regimen, and all 115 patients completing the treatment showed clinicoradiological resolution. Pleural thickening $(10-40 \mathrm{~mm})$ was observed in only nine subjects. In $37 \%$ of patients no direct evidence of $M$ tuberculosis in the pleura was obtained, so the diagnosis was based on the coexistence of a compatible clinical picture and "minor diagnostic criteria" (table).

Of the patients with only pleural disease only eight of $123(6 \cdot 8 \%)$ were lost during follow up. Others ${ }^{910}$ report good results with short regimens in patients with tuberculous pleurisy who also showed parenchymal infiltrates with negative sputum smears and positive culture.

Adverse effects attributable to the treatment were common $(20.7 \%)$ and higher than in other studies ${ }^{10}$ in which the drugs were administered only twice a week after the first month. In spite of this high incidence, side effects were usually trivial and it was only necessary to change treatment in three subjects.

This study was supported by a grant from "Fondo de Investigaciones de la Seguridad Social" (FISS no. 87/0986). The authors would like to thank all those involved in thi Medicine, Microbiology, and Biochemistry of our hospital.

1 Canetti G. Host factors and chemotherapy of tuberculosis. In: Canetti G, ed. Chemotherapy of tuberculosis. London Butterworths, 1964:175-82.

2 Dutt AK, Moers D, Stead WW. Short course chemotherapy for tuberculosis with mainly twice-weekly isoniazid and rifampin: community physicians' seven years experience rifampin: community physicians' seven years experienc

3 Snider DE, Long MW, Cross FS, Farrer LS. Six months isoniazid-rifampin therapy for pulmonary tuberculosis. Am Rev Respir Dis 1984;129:573-9.

4 Seibert AF, Haynes J Jr, Middleton R, Bass JB Jr. Tuberculous pleural effusion. Twenty years experience. Chest 1991;99:883-6.

5 Kumar S, Seshadri MS, Koshi G, John TJ. Diagnosing tuberculous pleural effusion: comparative sensitivity of mycobacterial culture and histopathology. $B M 71981 ; 283$ : 20-3.

6 Caminero JA. Bases bacteriológicas y principios generales del tratamiento de la infección y de la enfermedad tuberculosa. In: Tratamiento de la tuberculosis. Barcelona: Ediculosa. In: Tratamiento de la

7 Martin N, Gonzalez T. Control bacteriológico del tratamiento. In: Vidal R, de March P, eds. Tratamiento de la infección y enfermedad tuberculosa. Barcelona: Editorial Doyma, 1992:85-92

8 De March P. La transmisión de la resistencia al $M$ tuberculosi en los infectados por el VIH. Med Clin (Barc) 1994;102 98-100.

9 Dutt AK, Moers D, Stead WW. Smear-negative, culturepositive pulmonary tuberculosis. Six-month chemotherapy tuberculosis. Six-month chemotherapy with isoniazid and rifampin. Am Rev Respir Dis 1990;141:1232-5.

10 Dutt AK, Moers D, Stead WW. Tuberculous pleural effusion: six-month therapy with isoniazid and rifampin. $A m$ Rev Respir Dis 1992;145:1429-32. 